\title{
Coronary calcification as a predictor of cardiovascular mortality in advanced chronic kidney disease: a prospective long- term follow-up study
}

Marta Cano-Megías ${ }^{1 *}$, Pablo Guisado-Vasco ${ }^{2}$, Hanane Bouarich', Gabriel de Arriba-de la Fuente ${ }^{3}$, Patricia de Sequera-Ortiz ${ }^{4}$, Concepción Álvarez-Sanz ${ }^{1}$ and Diego Rodríguez-Puyol ${ }^{5}$

\begin{abstract}
Background: Patients with advanced chronic kidney disease (CKD) exhibit higher prevalence of coronary artery calcification $(\mathrm{CaC})$ than general population. $\mathrm{CaC}$ has been proposed as a risk factor for mortality in end-stage CKD, but most studies in the field are based on short-term follow-up.

Methods: We conducted a cohort, 10-year prospective longitudinal study of consecutive cases referred to the renal unit. A non-enhanced multislice coronary computed tomography was performed at baseline. CaC was assessed by Agatston method. Patients were stratified according to their $\mathrm{CaC}$ score: severe calcification group ( $\mathrm{CaCs}<400 \mathrm{HU}$ ) and mild-moderate calcification group ( $\mathrm{CaCs} \geq 400 \mathrm{HU})$. The overall and cardiovascular (CV) mortality, $\mathrm{CV}$ events, and factors potentially associated with $\mathrm{CaC}$ development were recorded.

Results: 137 patients with advanced CKD were enrolled and provided consent. Overall mortality rate was 58\%; 40\% due to CV events. The rate of overall mortality in the severe calcification group was $75 \%$, and $30 \%$ in the low calcification group, whereas the rate of CV mortality was $35 \%$ vs. $6 \%$, respectively $(p<0.001)$. The severe calcification group was older, had higher prevalence of type 2 diabetes mellitus, former cardiologic events, and lower albumin serum levels than the mild-moderate calcification group. In a multivariate Cox model, severe $\mathrm{CaC}$ was a significant predictor of CV mortality (HR 5.01; 95\%Cl 1.28 to $19.6, p=0.02$ ).

Conclusions: Among advanced CKD, there was a significantly increase of CV mortality in patients with severe CaCs during a 10-year follow-up period. CaCs could be a useful prognostic tool to predict CV mortality risk in CKD patients.
\end{abstract}

Keywords: Chronic kidney disease, Coronary artery calcification, Haemodialysis, Cardiovascular mortality, Coronary calcification score

\section{Background}

Cardiovascular (CV) disease is one of the leading causes of death and premature mortality among chronic kidney disease (CKD) patients [1]. In addition to classic risk factors for CV morbimortality, different uraemia related conditions such as malnutrition, chronic inflammation, accelerated atherosclerosis and endothelial dysfunction

\footnotetext{
* Correspondence: mcanomegias@gmail.com

${ }^{1}$ 'Principe de Asturias' University Hospital, Ctra Alcalá-Meco s/n. Alcalá de Henares, 28805 Madrid, Spain

Full list of author information is available at the end of the article
}

have been considered to be involved in the genesis of $\mathrm{CV}$ damage [2, 3]. Additionally, bone and mineral derangements are well-recognized complications of CKD that might result in aberrances in bone turnover and calcification of vascular or other soft tissues $[4,5]$.

$\mathrm{CV}$ calcifications affect most of CKD patients (6090\%) and these calcifications develop early in the course of the disease [1, 6-9]. In haemodialysis, previous studies have suggested that coronary calcification $(\mathrm{CaC})$ analysis could improve primary risk prediction of $\mathrm{CV}$ disease $[1,2,10]$. An elevated $\mathrm{CaC}$ score $(\mathrm{CaCs}>400$ 
$\mathrm{HU}$ ) could be associated with higher overall and CV mortality $[2,10]$. However, most of the studies have been performed after short follow-up, and scarce information is available concerning long-term prognosis [1]. Moreover, in advanced CKD and hemodialysis patients, the medial arterial wall calcification might predominate over atherosclerotic damage, and therefore it could be no underlying coronary obstructive atherosclerosis. Some studies have found poor correlation between CaCs measured by MSCT and coronary stenosis detected by coronary angiography [11-14]. Consequently, in these patients may predominate the non-atheromatous cardiovascular events [14]. Therefore, it is necessary to define the predictive role of $\mathrm{CaCs}$ for $\mathrm{CV}$ mortality in this population.

The primary aim of our study is to test, in long-term follow-up, the predictive value of $\mathrm{CaCs}$ detected by multi-layer spiral computed tomography (MSCT) for overall and CV mortality in advanced CKD patients, including those on hemodialysis. Secondary aims include assessing the prevalence of $\mathrm{CaC}$ and its effect on hospitalization due to $\mathrm{CV}$ events. As well as evaluating the potential clinical and biochemical factors involved in the development of severe $\mathrm{CaC}$.

\section{Methods}

We conducted a prospective, observational and 10-year follow-up study. All patients evaluated at the Renal Unit of 'Principe de Asturias' University Hospital during a 2-year period were considered for inclusion. A total of 137 patients with advanced CKD were enrolled. Inclusion criteria were as follows: age over 18 years, advance CKD disease (CKD stages 4-5) and patients on chronic haemodialysis (more than 6 months in the dialysis program). Exclusion criteria were as follows: acute kidney failure, pregnancy, a disease condition which could limit life expectancy to less than one year, and the inability to perform MSCT. Written informed consent was provided to all subjects. The Research Ethics Committee of the Hospital approved the study protocol.

As part of the initial evaluation in the renal unit, within one month prior to performing MSCT, in all cases a blood basal sample was collected for routine biochemistry analysis. All subjects underwent a synchronized MSCT to assess the basal CaC. A 16-detector MSCT Lightspeed Plus GE Medical System was used. Image processing was carried out in an Advantage Workstation 4.0 console. CaCs was calculated by adding the calcium score in the left main coronary artery, the left anterior descending, circumflex and right coronary artery. The CaCs described by Agatston [15] was calculated. It establishes a threshold of 130 Hounsfield Units (HU) to determine whether the lesions are calcified. The "Agatston score" incorporates the density of calcification, multiplying the calcification area by a weighted density coefficient. According to previously published information, patients may be classified into four groups according to baseline CaCs: no calcification (CaCs 0 $\mathrm{HU}$ ); mild calcification (CaCs 1-100 HU); moderate calcification (CaCs 101-400 HU) and severe calcification $(\mathrm{CaCs} \geq 400 \mathrm{HU})$ [16-18]. Our patients were stratified into two groups in order to analyse the proposed outcomes: severe calcification group $(\mathrm{CaCs} \geq 400 \mathrm{HU})$ and mild-moderate calcification group $(\mathrm{CaCs}<400 \mathrm{HU})$ [16].

Baseline clinical data were recorded from medical reports and are detailed in Table 1. The biochemical parameters included those related to renal function, bone mineral metabolism and classic cardiovascular risk variables. During the follow-up period, any new CV event that caused hospital admissions (heart failure, atrial fibrillation, stroke, ischemic heart disease) was recorded. For analysis purpose, we use a strategy of introducing a variable to the first event in time [17].

The overall mortality was defined as time from the recruitment moment to death from any cause, in-hospital or outpatient. CV mortality was considered as death due to myocardial infarction, congestive heart failure, cardiac arrhythmia, sudden cardiac death, peripheral vascular disease, or stroke.

\section{Statistical analysis}

Quantitative results were expressed as mean \pm standard deviation (SD) for continuous variables with normal distribution or as a median + interquartile range (IQR) in all other cases, in accordance with the Kolmogorov-Smirnov distribution test. Categorical variables are indicated as percentages related to the size of the sample. Subjects were split into two groups based on $\mathrm{CaCs}$ derived from baseline $\mathrm{CT}, \mathrm{CaCs} \geq 400 \mathrm{HU}$ and $\mathrm{CaCs}<400 \mathrm{HU}$. To compare both calcification groups, we used chi square test for binominal variables and Student $t$-test or Kruskal-Wallis test for quantitative variables, as suitable.

The influence of each variable on overall and CV mortality was assessed by means of a Cox proportional hazard models. The first stage consisted of a univariate analysis selecting those with a $p$-value $<0.1$ as statistically significant. Then, a multivariate Cox approach was carried out, using a backward strategy (p-value $<0.05$ ). The multivariate Cox regression model was used, assuming there is a maximum of one variable per each 10 events. Logistic regression analysis was used to identify the independent risk factors for high values of $\mathrm{CaCs}$. Overall and CV mortality was estimated using the Kaplan-Meier (KM) method and Mantel-Cox (log-rank test) to compare survival curves. The omnibus method was used to adjust the chi-square output. We also took into consideration the strategy reported by Detrano et al. [18] to study how a doubling of the CaCs influenced on overall and CV mortality of our series. To transform 
Table 1 Baseline patient characteristics and laboratory values

\begin{tabular}{|c|c|}
\hline Variable & N (\%)/Median (IQR)/Mean (SD) \\
\hline $\begin{array}{l}\text { Male (\%) } \\
\text { Female (\%) }\end{array}$ & $\begin{array}{l}74(54) \\
63(46)\end{array}$ \\
\hline Age (years) & $66(52-71)$ \\
\hline Haemodialysis (\%) & 85 (61.6) \\
\hline CKD stage 4-5 (\%) & $52(38.4)$ \\
\hline Haemodialysis vintage (months) & $25(10.0-53)$ \\
\hline Hypertension (\%) & $123(89)$ \\
\hline Diabetes mellitus (\%) & $38(27.7)$ \\
\hline Smoker (\%) & $30(18.4)$ \\
\hline Chronic ischemic heart disease (\%) & $27(20.1)$ \\
\hline Previous stroke event (\%) & $15(11.3)$ \\
\hline Previous cardiologic event (\%) & $35(26.3)$ \\
\hline Antiplatelet therapy (\%) & $48(35.0)$ \\
\hline Statin therapy (\%) & $59(43.1)$ \\
\hline Vitamin D therapy (\%) & $72(53.3)$ \\
\hline Calcium salt use (\%) & $73(54.1)$ \\
\hline Phosphate binder use (\%) & $57(42.5)$ \\
\hline Cinacalcet treatment (\%) & $9(6.70)$ \\
\hline CACl score (HU) & 137 \\
\hline $1(0)$ & $18(13.1)$ \\
\hline $2(1-100)$ & $18(13.1)$ \\
\hline $3(101-400)$ & $17(12.4)$ \\
\hline $4(\geq 400)$ & $84(61.3)$ \\
\hline Cholesterol (mg/dl) & $175( \pm 43.9)$ \\
\hline LDL- cholesterol (mg/dl) & $92.19( \pm 38.3)$ \\
\hline HDL-cholesterol (mg/dl) & $44.5( \pm 14.9)$ \\
\hline Triglycerides (mg/dl) & $142(85-214)$ \\
\hline Uric acid (mg/dl) & $6.99( \pm 1.54)$ \\
\hline $\mathrm{HbA1c}(\%)$ & $6.56( \pm 1.62)$ \\
\hline Albumin (g/dl) & $4.05( \pm 0.44)$ \\
\hline $\mathrm{eGFR}\left(\mathrm{ml} / \mathrm{min} / \mathrm{m}^{2}\right)$ & $11.5(4.8-22.7)$ \\
\hline Creatinine (mg/dl) & $7.51(3.52-10.0)$ \\
\hline Urea (mg/dl) & $151( \pm 48.9)$ \\
\hline Phosphorous (mg/dl) & $4.65(3.80-5.63)$ \\
\hline Calcium (mg/dl) & $9.38( \pm 0.72)$ \\
\hline Calcium-phosphorus product & $41.93(36.1-50.7)$ \\
\hline Bicarbonate (mmol/l) & $19.63( \pm 4.99)$ \\
\hline Intact PTH (pg/ml) & $220(94-413)$ \\
\hline TSH (ulU/ml) & $1.28(0.79-2.78)$ \\
\hline C-reactive protein (mg/l) & $5.9(3.13-13.1)$ \\
\hline
\end{tabular}

CaCs into a continuous variable, the base- 2 logarithm of the sum of the $\mathrm{CaCs}$ plus $1\left(\log _{2}[\mathrm{CaCs}+1]\right)$ was used. Each unit difference in the log-transformed $\mathrm{CaCs}$ represents a doubling of the score. Data were analysed using
SPSS version 20.0 (SPSS Software, Chicago, IL, USA). The significance level was set at $p<0.05$.

\section{Results}

The population-based sample was composed of 137 patients, 85 subjects (62\%) undergoing maintenance haemodialysis and 52 patients (38\%) with advanced CKD. Subjects were 74 males and 63 females, with a median age of 66 years (IQR 52 to 71). Haemodialysis vintage was 25 months (IQR 10-53). The median follow-up period was 87.5 months (29.5-111). Regarding renal replacement therapy, at baseline, two out five of patients in HD were dialyzed with a membrane of high dialytic efficacy and in four out five it was used a standard dialysis bath. The main baseline subject characteristics are outlined in Table 1.

\section{Variables associated with high CaCs}

The prevalence of $\mathrm{CaC}$ was $87 \%$ (range: 0 to $8798 \mathrm{HU}$ ). The median of CaCs was $600 \mathrm{HU}$ (IQR 70-1794). Those patients with severe $\mathrm{CaC}$ ( $\mathrm{CaCs} \geq 400 \mathrm{HU}$ ) were older, had a longer haemodialysis vintage, showed higher prevalence of type 2 diabetes, previous cardiologic events, and exhibited higher triglyceride serum concentration and lower serum albumin levels than mild-moderate $\mathrm{CaC}$ subjects $(\mathrm{CaCs}<400 \mathrm{HU})$ (Table 2.)

Variables that showed a significant association with severe $\mathrm{CaCs}(\geq 400 \mathrm{HU})$ were: age (OR 1.05 ; $95 \%$ confidence interval $[\mathrm{CI}]$ 1.02-1.08), haemodialysis (OR 2.85; 95\%CI 1.40-5.83), type 2 diabetes (OR 4.92; 95\%CI $1.89-12.8$ ), previous cardiologic events (OR 7.59; 95\%CI 2.49-23.2) and low serum albumin values (OR 2.92; $95 \% \mathrm{CI} 1.31-6.50)$. On the multivariate regression analysis, age (OR 1.07; 95\%CI 1.03-1.11), haemodialysis (OR 5.22; 95\% CI 1.88-14.5) and type 2 diabetes (OR 6.21 ; $95 \%$ CI 1.81-21.3) kept a statistically significant association with severe $\mathrm{CaCs}$.

\section{Mortality}

During the follow-up period, 58\% of subjects died and $40 \%$ of deaths were related to $\mathrm{CV}$ events. Considering overall mortality, $75 \%$ of patients $(n=60)$ were receiving haemodialysis and 25\% $(n=20)$ had advanced CKD. In terms of CV mortality, 78\% $(n=25)$ of subjects were on maintenance dialysis. Median overall survival, estimated by the inverted KM curve, was $44.6 \pm 3.7$ months ( $95 \%$ CI 37.4-51.8), while median CV survival was $39.1 \pm 5.6$ months (95\% CI 28.1 to 50.1 ).

Overall mortality rate according to baseline $\mathrm{CaCs}$ was $17 \%(n=3)$ in patients without $\mathrm{CaC}, 22 \%(n=4)$ in patients with mild $\mathrm{CaC}, 53 \%(n=9)$ in patients with moderate $\mathrm{CaC}$ and $75 \%(n=64)$ in patients with severe $\mathrm{CaC}$. Most of overall mortality events happened in group 4 (80\%). By KM analysis, patients with $\mathrm{CaCs} \geq 400 \mathrm{HU}$ had a significantly higher mortality compared to those with 
Table 2 Comparison between demographic, clinical and laboratory variables at study enrolment in patients with a high and a low coronary calcium score

\begin{tabular}{|c|c|c|c|}
\hline Variable & $\begin{array}{l}\mathrm{CaCs} \geq 400 \mathrm{HU} \\
(n=84)\end{array}$ & $\begin{array}{l}\mathrm{CaCs}<400 \mathrm{HU} \\
(n=53)\end{array}$ & $\mathrm{p}$ \\
\hline Age (years) & $65.2( \pm 11.7)$ & $56.3( \pm 14.9)$ & $<0.001^{*}$ \\
\hline $\begin{array}{l}\text { Haemodialysis vintage } \\
\text { (months) }\end{array}$ & $56.2( \pm 65.1)$ & $29.8( \pm 43.8)$ & $0.025^{*}$ \\
\hline Haemodialysis (\%) & $71.1(n=59)$ & $28.9(n=24)$ & 0.004 \\
\hline Hypertension (\%) & $62(n=76)$ & $38(n=46)$ & 0.58 \\
\hline Diabetes mellitus (\%) & $83.8(n=32)$ & $16.2(n=6)$ & $<0.001$ \\
\hline Smoker (\%) & $66.7(n=20)$ & $33.3(n=10)$ & 0.10 \\
\hline Previous stroke event (\%) & $15(n=12)$ & $5.8(n=3)$ & 0.16 \\
\hline $\begin{array}{l}\text { Previous cardiologic } \\
\text { event (\%) }\end{array}$ & $88.2(n=31)$ & $11.2(n=4)$ & $<0.001$ \\
\hline Antiplatelet use (\%) & $81.2(n=39)$ & $18.8(n=9)$ & $<0.001$ \\
\hline Calcium salt use (\%) & $63.4(n=46)$ & $36.6(n=26)$ & 0.59 \\
\hline Phosphate binder use (\%) & $48.8(n=40)$ & $31.4(n=15)$ & 0.07 \\
\hline Vitamin D use (\%) & $64.8(n=47)$ & $35.2(n=25)$ & 0.37 \\
\hline Cholesterol (mg/dl) & $170( \pm 39.6)$ & $183( \pm 49.1)$ & 0.085 \\
\hline LDL- cholesterol (mg/dl) & $87.8( \pm 36.7)$ & $101( \pm 40.2)$ & 0.12 \\
\hline HDL-cholesterol (mg/dl) & $43.1( \pm 11.1)$ & $44.1( \pm 11.6)$ & 0.72 \\
\hline Triglycerides (mg/dl) & $177( \pm 107)$ & $145( \pm 87.4)$ & $0.01^{*}$ \\
\hline Uric acid (mg/dl) & $6.97( \pm 1.59)$ & $7.01( \pm 1.48)$ & 0.89 \\
\hline $\mathrm{HbA1c}(\%)$ & $6.69( \pm 1.69)$ & $6.17( \pm 1.41)$ & 0.39 \\
\hline Albumin (g/dl) & $3.94( \pm 0.41)$ & $4.21( \pm 0.43)$ & 0.001 \\
\hline $\mathrm{eGFR}\left(\mathrm{ml} / \mathrm{min} / \mathrm{m}^{2}\right)$ & $12.3( \pm 9.65)$ & $16.8( \pm 10.9)$ & $0.045^{*}$ \\
\hline Creatinine (mg/dl) & $7.58( \pm 3.75)$ & $6.48( \pm 3.77)$ & $0.01^{*}$ \\
\hline Urea (mg/dl) & $152( \pm 48.9)$ & $150( \pm 49.8)$ & 0.75 \\
\hline Phosphorous (mg/dl) & $4.87( \pm 1.32)$ & $4.85( \pm 1.58)$ & $0.39^{*}$ \\
\hline Calcium (mg/dl) & $9.35( \pm 0.7)$ & $9.41( \pm 0.75)$ & 0.65 \\
\hline $\begin{array}{l}\text { Calcium - phosphorus } \\
\text { product }\end{array}$ & $45.3( \pm 12.1)$ & $45.6( \pm 15.4)$ & $0.48^{*}$ \\
\hline Bicarbonate (mmol/l) & $19.7( \pm 5.09)$ & $19.3( \pm 4.83)$ & 0.62 \\
\hline Intact PTH (pg./ml) & $333( \pm 414)$ & $324( \pm 326)$ & $0.52^{*}$ \\
\hline TSH (ulU/ml) & $4.52( \pm 10.9)$ & $1.8( \pm 1.1)$ & $0.48^{*}$ \\
\hline C-reactive protein (mg/l) & $15.7( \pm 27.6)$ & $12.8( \pm 23.4)$ & $0.43^{*}$ \\
\hline
\end{tabular}

*Kruskal-Wallis test, as appropriate

$\mathrm{CaCs}<400 \mathrm{HU}\left(\mathrm{X}^{2} 18.92, p<0.001\right)$ (Fig. 1a). There were no $\mathrm{CV}$ deaths in groups without or with mild $\mathrm{CaC}$. Most of $\mathrm{CV}$ deaths belonged to the severe calcification group (91\%, $n=29)$. By KM analysis, patients with $\mathrm{CaCs} \geq 400$ HU showed a significantly higher CV mortality compared to those with $\mathrm{CaCs}<400 \mathrm{HU}\left(\mathrm{X}^{2} 14.92, \mathrm{p}<0.001\right)$ too (Fig. 1b).

A total of $292 \mathrm{CV}$ events were observed during the follow-up period; 149 of them required admission to hospital. These CV events included: 82 heart failures, 17 atrial fibrillations, 29 ischemic heart diseases and 21 strokes. Figure 2 shows the unadjusted KM cumulative-curve for $\mathrm{CV}$ events incidence according to $\mathrm{CaCs}$. The differences among these curves were statistically significant $\left(\mathrm{X}^{2} 10.88, p=0.001\right)$.

\section{Coronary calcification as a predictor of total and cardiovascular mortality}

On univariate Cox analysis of the sample (Table 3), the predictive variables associated with overall mortality were: $\mathrm{CaCs} \geq 400 \mathrm{HU}$, age and previous cardiologic events. On multivariate Cox analysis, both age and previous cardiologic events still kept a statistically significant association with total mortality-according to omnibus test $\left(\mathrm{X}^{2} 10.18\right.$, $p=0.006)$ - while, only in haemodialysis patients, severe $\mathrm{CaCs}$ seemed to have tendency on overall mortality (HR 1.55; 95\%CI 0.84-2.87), although not reaching a statistical significance (Additional file 1).

The same strategy was carried out to assess the role of the $\mathrm{CaCs}$ as a predictor of $\mathrm{CV}$ mortality. On the univariate Cox analysis, those variables associated with $\mathrm{CV}$ mortality were: $\mathrm{CaCs} \geq 400 \mathrm{HU}$, previous stroke and serum calcium. On multivariate Cox analysis, $\mathrm{CaCs} \geq 400$ $\mathrm{HU}$ and serum calcium -according to omnibus test $\left(\mathrm{X}^{2}\right.$ 14.47, $p=0.002$ ) - still appeared to have an influence on CV mortality (Table 3).

Finally, in a separate analysis that considered $\mathrm{CaCs}$ as a continuous variable, we found that a doubling of the calcium score increased the estimated probability of both overall (HR 1.19; 95\%CI 1.1-1. 29) and CV (HR 1.43 ; $95 \%$ CI $1.19-1.72$ ) mortality by 19 and $43 \%$ respectively, during a median follow-up period of 87.5 (29.5111) months.

\section{Discussion}

In recent years, mortality of patients in haemodialysis has decreased due to improvements in technique. According to the United States Renal Data System, life expectancy of patients once they start haemodialysis ranges between 8 and 4.5 years. Increasing length of time on dialysis is a related to higher mortality rates [19].

In the present study, we explore the predictive value of $\mathrm{CaCs}$ for total and $\mathrm{CV}$ mortality in advanced CKD and haemodialysis population. Our results point out that $\mathrm{CaCs} \geq 400 \mathrm{HU}$ could be a predictor of higher CV mortality in this population, on a long-term basis. Unfortunately, we were not able to identify a clear relationship between $\mathrm{CaCs}$ and overall mortality in the whole sample. A possible limitation of the study might be the use of a relatively small sample size; therefore, further studies should be designed to explore this hypothesis.

In addition, we found that a doubling of the $\mathrm{CaC}$ score increased the estimated probability of CV mortality by approximately $43 \%$ in a 10 -year period. In the Detrano study, subjects aged 45 to 84 years with no clinical 


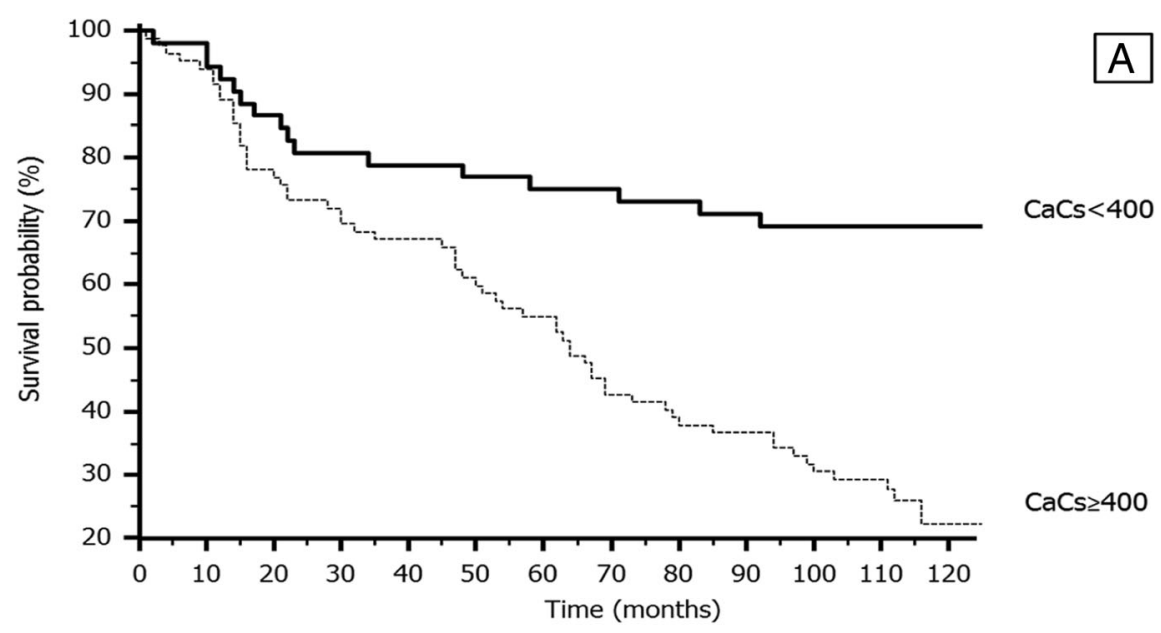

Number at risk

$\begin{array}{llllllllllllll}\mathrm{CaCs}<400 & 52 & 49 & 45 & 42 & 41 & 40 & 39 & 39 & 38 & 36 & 33 & 16 & 10 \\ \mathrm{CaCs} \geq 400 & 82 & 77 & 63 & 57 & 55 & 49 & 45 & 35 & 31 & 30 & 25 & 18 & 6\end{array}$

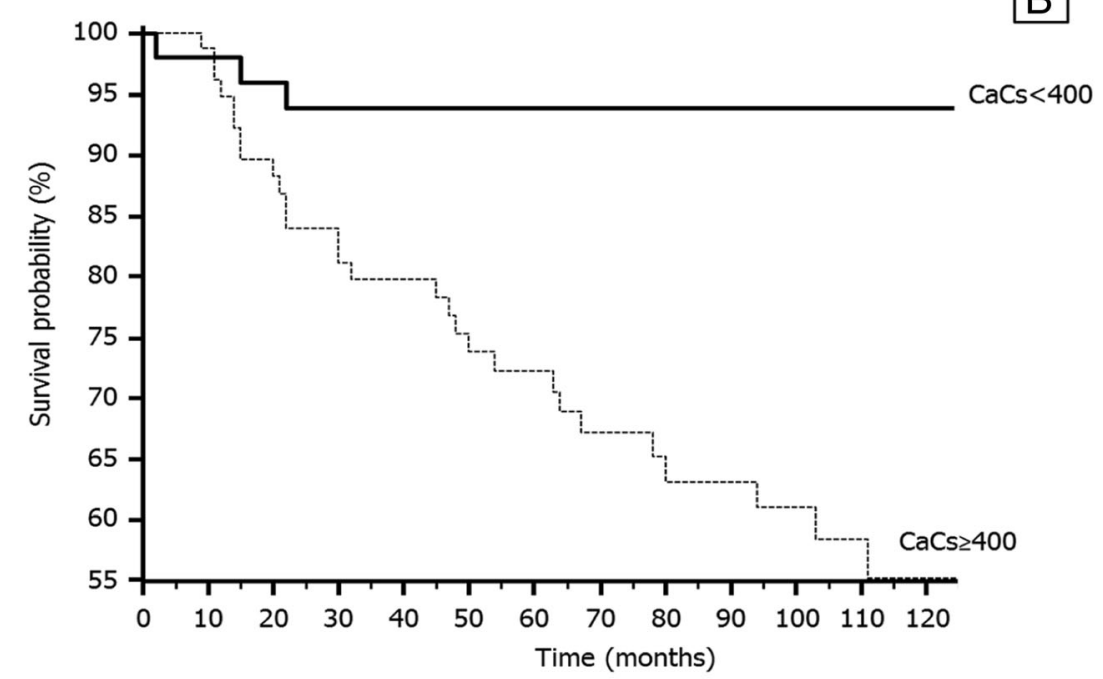

Number at risk

$\begin{array}{llllllllllllll}\mathrm{CaCs}<400 & 52 & 49 & 45 & 42 & 41 & 40 & 39 & 39 & 38 & 36 & 33 & 16 & 10 \\ \mathrm{CaCs} \geq 400 & 82 & 77 & 63 & 57 & 55 & 49 & 45 & 35 & 31 & 30 & 25 & 18 & 6\end{array}$

Fig. 1 Unadjusted Kaplan Meier cumulative-curves for overall mortality (a) and cardiovascular mortality (b) according to coronary arterial calcification score in Hounsfield Units (CaCs HU): Group with severe coronary calcification ( $\mathrm{CaCs} \geq 400 \mathrm{HU}$ ) and group with mild-moderate coronary calcification $(\mathrm{CaCs}<400 \mathrm{HU})$ are shown $p<0.001$

cardiovascular disease before enrolment were followed for a median of 3.8 years; authors found that a doubling of calcium score resulted in a $20 \%$ increase in the risk of a major coronary event (myocardial infarction or death from coronary heart disease) [18]. Our findings support previous studies that examined the relationship between $\mathrm{CaC}$ measured by MSCT and mortality in advanced CKD patients. These studies were performed mostly in advanced CKD patients and haemodialysis patients separately [10, 20-22], whereas we have preferred to include both types of patients together in our analysis. Moreover, to our knowledge, present data include the longest follow-up period in these patients until now.

In CKD patients, Watanabi et al. investigated a heterogeneous sample of 117 non dialyzed patients with CKD 


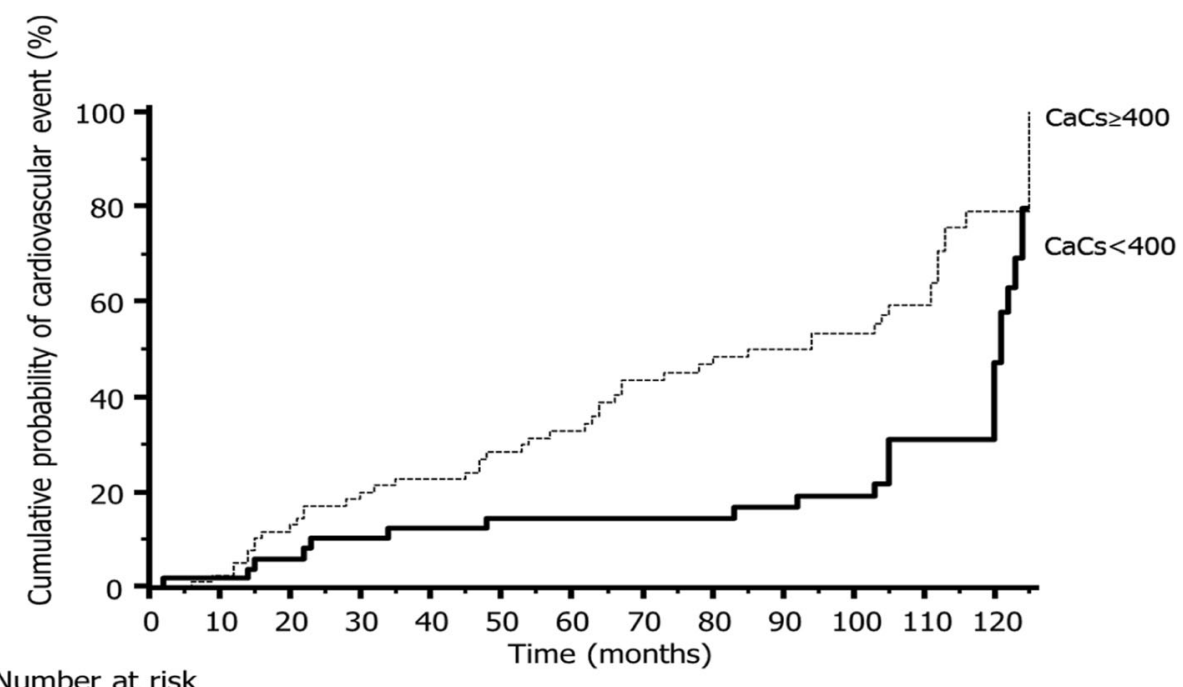

Number at risk

$\begin{array}{llllllllllllll}\mathrm{CaCs}<400 & 51 & 49 & 45 & 42 & 41 & 40 & 39 & 39 & 38 & 36 & 33 & 16 & 10 \\ \mathrm{CaCs} \geq 400 & 82 & 77 & 63 & 57 & 55 & 49 & 45 & 35 & 31 & 30 & 25 & 18 & 6\end{array}$

Fig. 2 Unadjusted Kaplan Meier cumulative curve for non-fatal cardiovascular events caused by coronary arterial calcium score in Hounsfield Units (CaCs HU); group with severe coronary calcification ( $\mathrm{CaCs} \geq 400 \mathrm{HU})$ and group with mild-moderate coronary calcification (CaCs< $400 \mathrm{HU})$ are shown. Non-fatal cardiovascular events include heart failure, ischemic heart disease, atrial fibrillation and stroke. $p=0.001$

stages 2 to 5 . After a follow-up period of 24 months, they found that the presence of $\mathrm{CaCs} \geq 400 \mathrm{HU}$ was associated with a shorter cardiovascular and hospitalization event-free time and a lower survival rate [20]. Recently, Chen et al. have addressed, in larger CKD cohort with a long follow-up, the association between $\mathrm{CaC}$ measured by MSCT and the risk of CV disease and mortality [23]. They found that $\mathrm{CaCs}$ is related to risk of $\mathrm{CV}$ diseases and improves risk predicted models. However, there are some notably differences with our current research: Chen et al. included only $20 \%$ of cases with an estimated glomerular filtration $<30 \mathrm{ml} / \mathrm{min}$, specifically excluded haemodialysis patients, and only considered overall mortality. Although their main conclusions are completely valid, their results did not provide information about the prognostic value of $\mathrm{CaC}$ concerning $\mathrm{CV}$ mortality in advanced $\mathrm{CKD}$, and it is in this aspect in which our results stress the value of this measurement in improving prognostic predictions.

Shantouf et al. found that haemodialysis patients with $\mathrm{CaCs} 0 \mathrm{HU}$ had a higher rate of 6-year event-free survival (89\%) compared to those with a $\mathrm{CaCs}>400 \mathrm{HU}$ (58\%). After adjustment for standard $\mathrm{CV}$ risk factors and bone-mineral metabolism parameters, they reported a higher total mortality in $\mathrm{CaCs}>400 \mathrm{HU}$ group [2].

Some authors have suggested that $\mathrm{CaCs}$ could be an independent predictor of all-cause mortality in haemodialysis. After adjusting for other CV risk factors, Matsuoka et al. found that the 5-year cumulative survival rate was significantly different between patients with low
CaCs (84\%) compared to those with high CaCs (68\%), although with an adjusted relative risk of death of 1.001 [10]. Block et al. (2007) described that baseline CaCs> $400 \mathrm{HU}$ was a significant predictor of all-cause mortality (HR 4.5, 95\%CI 1.33-15.14) in 127 incident haemodialysis patients during a 4-year follow-up period [22].

In a 7-year follow-up study, reported by Shimoyama [6], which was carried out in 200 haemodialysis patients, $51 \%$ of deaths were related to CV events. Much lower $\mathrm{CV}$ mortality was found in the lowest $\mathrm{CaCs}$ and similar results were reported in all-cause mortality. In a prospective study of a similar sample size, Noce et al. also found a significant difference in CV mortality in patients with $\mathrm{CaCs} \leq 400$, using Kaplan-Meier survival analysis, compared to those in the group of $\mathrm{CaCs}>400 \mathrm{HU} ; 49.7 \%$ died due to a major $\mathrm{CV}$ event during the follow-up period of 7 years [24].

In our study, we did not include CV disease subtypes in Cox analysis. However, it would have been interesting to analyse the subtypes of $\mathrm{CV}$ mortality in the haemodialysis group according to their $\mathrm{CaCs}$, since non-atheromatous $\mathrm{CV}$ events could predominate in these patients [14]. Matsushita et al. just assessed CV disease subtype. The prediction model with $\mathrm{CaC}$ was superior to intima media thickness and ankle-brachial index, only for coronary heart disease and heart failure prediction, regardless of CKD status [25].

As reported by other authors, we found a high prevalence of $\mathrm{CaC}$, ranging $0-8798 \mathrm{HU}$. This asymmetric distribution is consistent with other similar studies $[6,16$, 
Table 3 Univariate and multivariate Cox analysis of the factors associated with overall and cardiovascular mortality

\begin{tabular}{|c|c|c|c|c|c|c|c|c|}
\hline \multirow{3}{*}{ Variable } & \multicolumn{4}{|l|}{ Overall mortality } & \multicolumn{4}{|c|}{ Cardiovascular mortality } \\
\hline & \multicolumn{2}{|l|}{ Univariate Cox } & \multicolumn{2}{|l|}{ Multivariate Cox } & \multicolumn{2}{|c|}{ Univariate Cox } & \multicolumn{2}{|l|}{ Multivariate Cox } \\
\hline & HR (IC 95\%) & $p$ & HR (IC 95\%) & $p$ & HR (IC 95\%) & $\mathrm{p}$ & HR (IC 95\%) & $p$ \\
\hline Age & $1.03(1.00-1.05)$ & 0.034 & $1.03(1.01-1.05)$ & 0.02 & $1.02(0.98-1.07)$ & 0.24 & - & \\
\hline Male & $1.23(0.72-2.10)$ & 0.45 & - & & $1.19(0.57-2.50)$ & 0.65 & - & \\
\hline Haemodialysis & $1.2(0.71-2.03)$ & 0.5 & - & & $1.49(0.64-3.44)$ & 0.35 & - & \\
\hline Haemodialysis vintage & $1.0(0.99-1.00)$ & 0.95 & - & & $1(0.99-1.00)$ & 0.38 & - & \\
\hline Hypertension & $1.43(0.71-2.88)$ & 0.31 & - & & $2.16(0.61-7.60)$ & 0.23 & - & \\
\hline Diabetes Mellitus & $1.12(0.63-2.00)$ & 0.69 & - & & $0.84(0.34-2.09)$ & 0.71 & - & \\
\hline Smoker & $1.18(0.57-2.43)$ & 0.66 & - & & $3.19(0.91-11.2)$ & 0.07 & - & \\
\hline History of stroke event & $0.63(0.32-1.24)$ & 0.18 & - & & $0.31(0.11-0.87)$ & 0.03 & $0.56(0.16-1.94)$ & 0.36 \\
\hline History of cardiologic event & $1.63(0.92-2.88)$ & 0.09 & $1.81(1.09-3.03)$ & 0.02 & $1.3(0.6-2.82)$ & 0.51 & - & \\
\hline Chronic ischemic heart disease & $1.82(0.97-3.41)$ & 0.06 & & & $1.58(0.67-3.72)$ & 0.30 & - & \\
\hline Antiplatelet treatment & $1.15(0.67-1.96)$ & 0.62 & - & & $0.91(0.44-1.88)$ & 0.80 & - & \\
\hline Statin treatment & $1.43(0.83-2.47)$ & 0.20 & - & & $1.36(0.65-2.83)$ & 0.42 & - & \\
\hline Vit. $D$ treatment & $1.23(0.72-2.09)$ & 0.44 & - & & $1.36(0.65-2.84)$ & 0.41 & - & \\
\hline Calcium salt use & $1.01(0.59-1.74)$ & 0.98 & - & & $1.86(0.86-4.01)$ & 0.12 & - & \\
\hline Phosphate binder use & $0.64(0.37-1.13)$ & 0.13 & - & & $1.87(0.88-4.01)$ & 0.11 & - & \\
\hline Cinacalcet treatment & $0.62(0.26-1.47)$ & 0.28 & - & & $0.41(0.12-1.41)$ & 0.16 & - & \\
\hline Cholesterol & $1.00(0.99-1.00)$ & 0.59 & - & & $1.00(0.99-1.01)$ & 0.77 & - & \\
\hline LDL-cholesterol & $0.99(0.99-1.00)$ & 0.20 & - & & $1.00(0.99-1.01)$ & 0.65 & - & \\
\hline HDL-cholesterol & $1.01(0.99-1.01)$ & 0.50 & - & & $1.00(0.99-1.00)$ & 0.82 & - & \\
\hline Triglycerides & $0.99(0.995-1)$ & 0.02 & & & $1.00(0.73-1.30)$ & 0.08 & & \\
\hline Uric acid & $0.95(0.82-1.11)$ & 0.50 & - & & $0.97(0.73-1.30)$ & 0.83 & - & \\
\hline $\mathrm{HbA1c}$ & $1.21(0.94-1.53)$ & 0.14 & - & & $1.21(0.83-1.77)$ & 0.32 & - & \\
\hline Albumin & $1.06(0.58-1.93)$ & 0.86 & - & & $0.40(0.12-1.35)$ & 0.14 & - & \\
\hline Creatinine & $0.99(0.93-1.05)$ & 0.64 & - & & $0.92(0.84-1.01)$ & 0.08 & - & \\
\hline Urea & $1.00(0.99-1.01)$ & 0.32 & - & & $1.00(0.99-1.00)$ & 0.24 & - & \\
\hline Phosphorous & $0.90(0.76-1.06)$ & 0.19 & - & & $1.06(0.79-1.41)$ & 0.72 & - & \\
\hline Calcium & $0.93(0.68-1.30)$ & 0.68 & - & & $0.39(0.19-0.84)$ & 0.02 & $0.37(0.18-0.78)$ & 0.01 \\
\hline Ca X P product & $0.99(0.97-1.00)$ & 0.16 & - & & $1.00(0.12-1.35)$ & 0.14 & - & \\
\hline Bicarbonate & $1.03(0.97-1.09)$ & 0.4 & - & & $1.11(1-1.23)$ & 0.06 & & \\
\hline Intact PTH & $1.00(0.99-1.00)$ & 0.94 & - & & $1.00(0.99-1.00)$ & 0.30 & - & \\
\hline TSH & $1.07(1.01-1.14)$ & 0.03 & & & $1.05(0.98-1.12)$ & 0.15 & - & \\
\hline CRP & $1.00(0.99-1.007)$ & 0.76 & - & & $1.02(0.98-1.07)$ & 0.26 & - & \\
\hline $\mathrm{CaCs} \geq 400 \mathrm{HU}$ & $2.15(0.95-4.84)$ & 0.07 & $1.55(0.84-2.87)$ & 0.16 & $5.91(1.18-29.48)$ & 0.03 & $5.01(1.28-19.59)$ & 0.02 \\
\hline
\end{tabular}

26]. Moreover, patients with high $\mathrm{CaCs}$ had worse renal function than those with low CaCs. Also, there were more haemodialysis patients in the group of severe calcifications. This finding supports the inverse relationship between glomerular filtration rate and $\mathrm{CaC}[1,7]$. As reported in previous studies, we found that patients with high $\mathrm{CaCs}$ were older, with higher prevalence of previous cardiologic events and type 2 diabetes [2, 8, 10, 27]. It is well known that diabetes is a risk factor for developing atherosclerosis and vascular calcification [28, 29].
Our data showed that patients with high $\mathrm{CaCs}$ had lower albumin levels than patients with mild or moderate $\mathrm{CaC}$. Malnutrition-inflammation complex syndrome is a common phenomenon in dialysis patients, and is related to increased morbidity and mortality. In dialysis patients, there seems to be an association between malnutrition-inflammation complex syndrome and vascular calcification [30, 31]. Therefore, lower albumin level, as a marker of malnutrition and inflammation, could be a risk marker of $\mathrm{CaC}$. This finding, 
however, needs to be validated conducting larger sample prospective studies.

We did not find a significant association between $\mathrm{CaC}$ and any biochemical parameter related to mineral metabolism or other traditional CV risk parameters. This lack of association could be explained by the small sample size, the study design or the clinical characteristics of our cohort. It should be mentioned that biochemical parameters were measured only once at baseline, and a single baseline laboratory value may not reflect the time-averaged exposure.

Traditionally, hypercalcemia, hyperphosphatemia and secondary hyperparathyroidism have been associated with vascular calcification in patients with CKD. However, it has been described that excessive suppression of $\mathrm{PTH}$, or relative hypoparathyroidism, leads to a decrease in bone remodelling or adynamic bone. It is also related to a greater progression of vascular and coronary calcification. Therefore, calcium and PTH levels do not always are correlated with net calcium balance and vascular calcification severity [32].

Therapeutic changes were not recorded, so might be they have had some influence on endpoints. In relation to this point, it is known that CKD and dialysis patients treated with non-calcium-based phosphate binders have a reduction in all-cause mortality compared with those that use calcium-based phosphate binders [33, 34]. Besides, it has been reported that a low dialysate calcium level could reduce progression rate of $\mathrm{CaC}$ in haemodialysis patients [35]. Besides, the treatment provided to patients was aimed to control disturbances of mineral metabolism adequately, and this pharmacological intervention could have conditioned the results obtained. Another potential bias might be related to the design of the enrolment if it considered that those patients of incident haemodialysis and severe $\mathrm{CaC}$ might experience a premature death ( $<6$ months). Though, we set a minimum period of 6 months of permanence in the hemodialysis program to minimize this theoretical bias. Thus, those cases incident in hemodialysis, whose death in a period inferior to 6 months, were excluded. All enrolled cases were previously followed up in the Nephrologist outpatient office. And, in fact, the ANSWER study reports that the most potent predictor of early mortality was inadequate pre-dialysis treatment [36].

Moreover, $\mathrm{CaC}$ in our cohort was only measured just once, at baseline conditions. Therefore, we couldn't report number of patients with $\mathrm{CaCs}<400 \mathrm{HU}$ who have change to $\mathrm{CaCs}>400 \mathrm{HU}$ during the follow up.

\section{Conclusions}

We conclude that, within the limits of our relatively small sample size, $\mathrm{CaC}$ is highly prevalent in advanced CKD patients. Age, diabetes and haemodialysis therapy may be associated with $\mathrm{CaC}$ severity. $\mathrm{CaCs}$ seems to be a good long-term predictor of CV mortality in patients with advanced CKD, but larger prospective studies are needed to confirm the clinical utility of performing routine MSCT in this population in order to assess CV risk.

\section{Additional file}

Additional file 1: Tables S1 and S2. Description of cardiovascular events and mortality. Multivariate proportional Cox analysis in the haemodialysis group. (DOCX $16 \mathrm{~kb}$ )

\section{Abbreviations}

CaC: Coronary calcification; CaCs: Coronary calcification score; Cl: Confidence interval; CKD: Chronic kidney disease; CV: Cardiovascular; HD: Haemodialysis; HR: Hazard ratio; HU: Hounsfield Units; IQR: Interquartile range; KM: KaplanMeier; MSCT: Multi-layer spiral computed tomography; OR: Odds ratio; SD: Standard deviation

\section{Acknowledgements}

None.

\section{Funding}

The present study has not provided by any grant, funding or financial support from any party.

\section{Availability of data and materials}

Data supporting the results reported in the present manuscript, according to the country legislation. The datasets used and/or analyzed during the current study available from the corresponding author on reasonable request.

\section{Authors' contributions}

MCM and PGV acquired, analysis, interpreted the collected data, and drafting of the manuscript. CAS assessed the scores obtained in the images studies and interpreted them. DRP and HB contributes to the design, drafting and promote equally to the direction of the research. PSO and GAF contributes to conception of the research and data acquisition. All authors critically review the article for important intellectual content and approved the final version of the manuscript. All authors are accountable for all aspects of the work in ensuring that questions related to the accuracy or integrity of any part of the article are appropriately investigated and resolved.

\section{Ethics approval and consent to participate}

The research has been approved by the local ethics committee, from the 'Príncipe de Asturias' University Hospital (date 12/1/2004). All participants have signed a consent form specifically design for current study.

\section{Consent for publication}

Not applicable.

\section{Competing interests}

The authors declare that they have no competing interests.

\section{Publisher's Note}

Springer Nature remains neutral with regard to jurisdictional claims in published maps and institutional affiliations.

\section{Author details}

${ }^{1}$ 'Principe de Asturias' University Hospital, Ctra Alcalá-Meco s/n. Alcalá de Henares, 28805 Madrid, Spain. ${ }^{2}$ European University, Internal Medicine, Ruber Juan Bravo Hospital, Juan Bravo St 39-49, ZP 28006 Madrid, Spain.

${ }^{3}$ Guadalajara University Hospital, Donante de Sangre St S/n, ZP 19002 Guadalajara, Castilla La Mancha, Spain. ${ }^{4}$ Infanta Leonor' University Hospital, Gran vía del Este, 80, 28031 Madrid, Spain. ${ }^{5}$ Research Foundation of 'Principe de Asturias' University Hospital, Ctra Alcalá-Meco s/n, Alcalá de Henares, 28805 Madrid, Spain. 
Received: 19 September 2017 Accepted: 30 April 2019

Published online: 28 May 2019

\section{References}

1. Bashir A, Moody WE, Edwards NC, Ferro CJ, Townend JN, Steeds RP. Coronary artery calcium assessment in CKD: utility in cardiovascular disease risk assessment and treatment? Am J Kidney Dis. 2015;65(6):937-48.

2. Shantouf RS, Budoff MJ, Ahmadi N, et al. Total and individual coronary artery calcium scores as independent predictors of mortality in haemodialysis patients. Am J Nephrol. 2010;31(5):419-25.

3. Turkmen K, Kayikcioglu H, Ozbek O, Solak Y, Kayrak M, Samur C, et al. The relationship between Epicardial adipose tissue and malnutrition, inflammation, atherosclerosis/calcification syndrome in ESRD patients. Clin J Am Soc Nephrol. 2011;6:1920-5.

4. London GM. Mechanisms of arterial calcifications and consequences for cardiovascular function. Kidney Int; Suppl (2011). 2013;3(5):442-5.

5. Demer LL, Tintut Y. Vascular calcification: pathobiology of a multifaceted disease. Circulation. 2008;117(22):2938-48.

6. Shimoyama Y, Tsuruta Y, Niwa T. Coronary artery calcification score is associated with mortality in Japanese haemodialysis patients. J Ren Nutr. 2012;22(1):139-42.

7. Budoff MJ, Rader DJ, Reilly MP, Mohler ER 3rd, Lash J, Yang W, et al. Relationship of estimated GFR and coronary artery calcification in the CRIC (chronic renal insufficiency cohort) study. Am J Kidney Dis. 2011;58(4):519-26.

8. Russo D, Palmiero G, De Balsio AP, Balleta MM, Andreucci VE. Coronary artery calcification in patients with CRF not undergoing Dialysis. Am J Kidney Dis. 2004;44(6):1024-30.

9. Tomiyama C, Higa A, Dalboni MA, Cendoroglo M, Draibe SA, Cuppari $L$. The impact of traditional and non-traditional risk factors on coronary calcification in pre-dialysis patients. Nephrol Dial Transplant. 2006;21(9):2464-71.

10. Matsuoka M, Iseki K, Tamashiro M, et al. Impact of high coronary artery calcification score (CACS) on survival in patients on chronic haemodialysis. Clin Exp Nephrol. 2004;8(1):54-8.

11. Sharples EJ, Pereira D, Summers $\mathrm{S}$, et al. Coronary artery calcification measured with electron-beam computerized tomography correlates poorly with coronary artery angiography in dialysis patients. Am J Kidney Dis. 2004; 43(2):313-9.

12. Haydar AA, Hujairi NM, Covic AA, Pereira D, Rubens M, Goldsmith DJ. Coronary artery calcification is related to coronary atherosclerosis in chronic renal disease patients: a study comparing EBCT-generated coronary artery calcium scores and coronary angiography. Nephrol Dial Transplant. 2004; 19(9):2307-12.

13. Tong LL, Mehrotra R, Shavelle DM, Budoff M, Adler S. Poor correlation between coronary artery calcification and obstructive coronary artery disease in an endstage renal disease patient. Hemodial Int. 2008;12(1):16-22.

14. Bover J, Ureña-Torres P, Górriz JL, Lloret MJ, da Silva I, Ruiz-García C, et al. Cardiovascular calcifications in chronic kidney disease: potential therapeutic implications. Nefrol. 2016;36(6):597-608.

15. Agatston AS, Janowitz WR, Hildner FJ, et al. Quantification of coronary artery calcium using ultrafast computed tomography. J Am Coll Cardiol. 1990;15:827-32.

16. Raggi P, Boulay A, Chasan-Taber S, Amin A, Dillon M, Burke SK, et al. Cardiac calcification in adult Haemodialysis patients. A link between end-stage renal disease and cardiovascular disease? J Am Coll Cardiol. 2002;39(4):695-701.

17. Rauch G, Kieser M, Binder H, Bayes-Genis A, Jahn-Eimermacher A. Time-tofirst-event versus recurrent-event analysis: points to consider for selecting a meaningful analysis strategy in clinical trials with composite endpoints. Clin Res Cardiol. 2018;107(5):437-43.

18. Detrano R, Guerci AD, Carr JJ, Bild DE, Burke G, Folsom AR, et al. Coronary calcium as a predictor of coronary events in four racial or ethnic groups. $N$ Engl J Med. 2008;358(13):1336-45.

19. Collins AJ, Foley RN, Herzog C, Chavers BM, Gillbertson D, Ishani A, et al. Excerpts from the US renal data system 2009 annual data report. Am J Kidney Dis. 2010;55(1 Suppl 1):S1-S420 A6-7.

20. Watanabe R, Lemos MM, Manfredi SR, Draibe SA, Canziani ME. Impact of cardiovascular calcification in non-dialyzed patients after 24 months of follow-up. Clin J Am Soc Nephrol. 2010;5(2):189-94.

21. Wilkieson TJ, Rahman M, MO GAS, Voss M, Ingram AJ, Ranganath N, et al. Coronary artery calcification, cardiovascular events, and death: a prospective cohort study of incident patients on hemodialysis. Can J Kidney Health Dis. 2015;2:29.
22. Block GA, Raggi P, Bellasi A, Kooienga L, Spiegel DM. Mortality effect of coronary calcification and phosphate binder choice in incident haemodialysis patients. Kidney Int. 2007;71:438-41.

23. Chen J, Budoff MJ, Reilly MP, Yang W, Rosas SE, Rahman M, et al. Coronary artery calcification and risk of cardiovascular disease and death among patients with chronic kidney disease. JAMA Cardiol. 2017;2(6):635-43.

24. Noce A, Canale MP, Capria A, Rovella V, Tesauro M, Splendiani G, et al. Coronary artery calcifications predict long term cardiovascular events in non-diabetic Caucasian haemodialysis patients. Aging (Albany NY). 2015; 7(4):269-79.

25. Matsushita K, Sang Y, Ballew SH, Shlipak M, Katz R, Rosas SE, et al. Subclinical atherosclerosis measures for cardiovascular prediction in CKD. J Am Soc Nephrol. 2015;26(2):439-47.

26. Goodman WG, Goldin J, Kuizon BD, Yoon C, Gales B, Sider D, et al. Coronary-artery calcification in young adults with end stage renal disease who are undergoing dialysis. N Engl Med. 2000;342(20):1478-83.

27. Fensterseifer DM, Karohl C, Schvartzman P, Costa CA, Veronese FJ. Coronary calcification andits association with mortality in haemodialysis patient. Nephrology (Carlton). 2009;14(2):164-70.

28. Wu M, Rementer C, Giachelli CM. Vascular calcification: an update on mechanisms and challenges in treatment. Calcif Tissue Int. 2013;93(4):365-73.

29. Snell-Bergeon JK, Budof fMJ, Hokanson JE. Vascular calcification in diabetes. Mechanisms and implications. Curr Diab Rep. 2013;13:391.

30. Ikee R, Honda K, Oka M, Maesato K, Mano T, Moriya H, Ohtake T, et al. Association of Heart Valve Calcification with malnutrition-inflammation complex syndrome, b2-microglobulin, and carotid intima media thickness in patients on Haemodialysis. Ther Apher Dial. 2008;12(6):464-8.

31. Zhang K, Gao J, Chen J, Liu X, Cai Q, Liu P, Huang H. MICS, an easily ignored contributor to arterial calcification in CKD patients. Am J Physiol Renal Physiol. 2016;311(4):663-70.

32. Bover J, Ureña P, Brandenburg V, Goldsmith D, Ruiz C, DaSilva I, et al. Adynamic bone disease: from bone to vessels in chronic kidney disease. Semin Nephrol. 2014 Nov;34(6):626-40.

33. Jamal SA, Vandermeer B, Raggi P, Mendelssohn DC, Chatterley T, Dorgan M, et al. Effect of calcium-based versus non-calcium-based phosphate binders on mortality in patients with chronic kidney disease: an updated systematic review and meta-analysis. Lancet. 2013;12(382):1268-77.

34. Di lorio B, Bellasi A, Russo D. On behalf of the independent study investigators. Mortality in kidney disease patients treated with phosphate binders: a randomized study. Clin J Am Soc Nephrol. 2012;7:487-93.

35. Ok E, Asci G, Bayraktaroglu S, Toz H, Ozkahya M, Yilmaz M, et al. Reduction of dialysate calcium level reduces progression of coronary artery calcification and improves low bone turnover in patients on hemodialysis. J Am Soc Nephrol. 2016;27(8):2475-86.

36. Pérez-García R, Martín-Malo A, Fort J, et al. Baseline characteristics of an incident hemodialysis population in Spain: results from ANSWER - a multicenter, prospective, observational cohort study. Nephrol Dial Transplant. 2009;24:578-88.

Ready to submit your research? Choose BMC and benefit from:

- fast, convenient online submission

- thorough peer review by experienced researchers in your field

- rapid publication on acceptance

- support for research data, including large and complex data types

- gold Open Access which fosters wider collaboration and increased citations

- maximum visibility for your research: over $100 \mathrm{M}$ website views per year

At $\mathrm{BMC}$, research is always in progress.

Learn more biomedcentral.com/submissions 